\title{
Medical Student Education
}

\section{Decentralized Medical Education in Rural Communities: The Circuit Rider Connection}

\author{
Martha McGrew, MD; Brian Solan, MD, MPH; Tina Hoff, MA; Betty Skipper, PhD
}

Background and Objectives: Successful community-based medical education requires an ongoing relationship among the school, medical students, and community preceptors. The use of medical school faculty as "circuit riders" helps to develop and maintain these relationships. We studied the benefits, challenges, and barriers as seen by faculty participating in circuit riding activities at the University of New Mexico. Methods: All 43 faculty circuit riders from the most recent academic year were asked to complete an anonymous electronic survey. Ranked responses and free text comments were included. Analysis of ranked items by years as university faculty and years of experience circuit riding was performed. Results: Commonly cited reasons for faculty participation in circuit riding included (1) enjoyment of working with medical students, (2) support for rural/community-based education, and (3) interactions with community preceptors. Barriers primarily related to time included (1) difficulty getting time away from clinical activities and (2) coordinating the faculty members', community preceptors', and students' schedules. Conclusions: For faculty circuit riders, commitment to medical student education in the community is the most common reason for participation in this program. Schools using this model will need to address the time commitment involved.

(Fam Med 2008;40(5):321-5.)

Less than $1 \%$ of medical care is delivered in tertiary care hospitals, yet, for many medical students, this remains the major site of their medical education. ${ }^{1}$ As schools move to include training sites that are more reflective of societal needs, many challenges emerge. Rural and ambulatory preceptors and sites must deal with the time constraints of teaching in busy practices with decreasing revenues and isolation of the rural communities from the medical school. The variation of educational experiences at different clinical sites must also be addressed. ${ }^{2}$ As required by the Liaison Committee on Medical Education, comparable education experiences and methods of evaluation must be used across different instructional sites. ${ }^{3}$

Other programs have described site visits at community training locations. "Academic detailing" by a faculty member, clerkship director, or residency director is one strategy. Two well known programs, WWAMI (a partnership among the states of Wyoming,

From the Department of Family and Community Medicine, University of New Mexico.
Washington, Alaska, Montana, and Idaho) and University of Massachusetts (UMASS) Medical School also use a few select faculty members in similar roles with their preceptorship program to support students and community faculty (personal communication). Our study was designed to find the motivating factors and barriers faced by faculty participating as "circuit riders" who visit community training sites in a rural Southwestern state.

\section{Description of the Program \\ History and Logistics}

In 1979, with piloting of a primary care curriculum, a small group of first-year medical students were sent to rural communities during their first year of medical school. Since 1993 this has been required of all students. This experience, called the Practical Immersion Experience (PIE), takes place in the summer between the first and second year of medical school. Students spend 8 weeks with a volunteer community preceptor, usually in rural sites. The preceptors are in primary care, with two thirds being in family medicine. Students live in the community, spending 3 to 5 half days of each week working in clinic. The remainder of their time is spent in independent study, completing geriatric and public 
health activities and participating in a community project.

There are more than 70 students and 70 preceptors participating in the 8-week PIE every summer. Due to the long distances from the university and the length of this rural experience, it was not feasible to have a single faculty member or single department provide all of the community site visits. To meet these demands, the circuit rider system was developed as an integral part of the PIE using multiple departments from the university medical school.

Each PIE student is assigned a faculty member from the university who serves as a circuit rider. Circuit riders include clinical faculty and basic scientists. Each is assigned one to three students. Circuit riders prepare for their responsibilities at a 1-hour orientation; clinical faculty receive $\mathrm{CME}$ credit for their attendance.

\section{Faculty Responsibilities}

Circuit riders meet with their students before the PIE begins. They review the students' summer learning prescription and provide direction and identification of pertinent and realistic learning goals to be achieved during the PIE. Course expectations, ways of maintaining communication, and arrangements for an on-site meeting are discussed. This meeting takes less than 1 hour.

The circuit riders contact the students and the community preceptors during the first 2 weeks of the PIE. Any early problems are identified, and methods to improve the rotation are discussed. Circuit riders help students locate high-quality resources for their studies and ensure that the students are adjusting to the change in location.

Halfway through the rotation, circuit riders drive or fly to the community preceptors' sites. This may be a day or overnight trip. The circuit riders interview the preceptors and discuss the students' progress. The students are observed by the circuit riders during clinical interactions with patients and their preceptors. Their clinical write-ups and researched learning issues from the last 4 weeks are reviewed. Students receive feedback on their performances to date as a formative evaluation. Students also self-assess their performance. New learning prescriptions are developed to be implemented over the rest of the rotation. It is important to note that circuit riders provide students with feedback and evaluation in addition to that given by the preceptors. Circuit riders are encouraged to take students, preceptors, and key preceptor staff to breakfast, lunch, or dinner while on site.

Circuit riders also provide support for the community preceptors. They mediate problems that occur between preceptors and students, identify resources available for the preceptors in the area of teaching and patient care, and bring the good will of the university to the outlying communities.
At the end of the PIE, students meet again with their circuit riders, on site or on the university campus. The students' completed requirements are reviewed. The circuit riders complete summative evaluations of the students' performances. Recommendations for improvement over the next year are discussed individually with the students during this 1-hour meeting.

\section{The Cost of Circuit Riding}

Circuit riders are reimbursed by the university for expenses incurred during the on-site visit. The cost of each circuit ride is dependent on the method of transportation, lodging for overnight visits and meals for the circuit rider, preceptor, and any preceptor staff. The average reimbursement of a circuit ride is $\$ 150$. This does not account for lost revenue for those with clinical responsibilities. Circuit riding counts toward the "credit" given by the university to faculty and departments for educational activities, which, in turn, is linked to their year-end evaluations and department teaching goals.

\section{Monitoring Circuit Rider Activity}

The Preceptorship Office coordinates and tracks the circuit riders' activities, including reimbursements and collection of required evaluations. Students do not receive credit for the experience without two completed circuit rider evaluations. In the required end of rotation evaluation, students may comment on the value of the circuit rider visit. This allows the Preceptorship Office and the circuit rider to receive ongoing feedback on the effectiveness of the program. Students' comments include positives such as "It was very helpful to have Dr $\mathrm{X}$ come visit. I had a much better idea of what I needed to do to improve my write-ups." "Having someone [the circuit rider] watching me do [a] history and physical was very stressful, but I got good feedback." Some students did not see any value in the visit, such as, "It seemed like the circuit rider visit was redundant. My preceptor was already doing all those things." "My circuit rider was way too picky. What the university wants and what happens out in the real world doesn't seem to be connected." Preceptors are not asked to evaluate the circuit ride. Most unsolicited comments have been positive. "It meant a lot to me to have someone from the University come all the way out here to see what we do [with the students]. We put a great deal of effort into teaching ... it is nice to have someone recognize our efforts." "I had a much better idea of what I should be working on with my student after the [circuit rider] visit. I didn't realize the level at which students were functioning during [the] PIE."

\section{Program Evaluation}

As part of routine program assessment, surveys were delivered to all circuit riders who had participated in the program at any time over the last year. The surveys 
gathered demographic data on the circuit riders, frequency and years of circuit riding, site preference, reasons for participation in the program, and positive and negative aspects of the experience. No individual identifying information was collected about the survey. The University of New Mexico Institutional Review Board approved the research protocol.

We asked circuit riders to rank a given set of reasons for participation in the program, their circuit ride location choice, and reasons for any lapses in yearly participation. Open-ended questions soliciting comments on their experiences were also incorporated. These included their perceived value of circuit riding and the most difficult aspect of their experience. The authors reviewed the comments and grouped them in general categories or themes. Some respondents did not rank all items related to reasons for choosing to participate in circuit riding. Therefore, results for each item are presented as percentages of respondents choosing to rank the item and the mean ranking for those who ranked the item. Ranked responses were compared by years as faculty at the university and years of circuit riding using Fisher's exact tests for the percentages responding items and $t$ tests for the mean rankings.

\section{Results}

Of a total of 43 participants, $91 \%$ responded. Faculty specialty, years of experience circuit riding, and years of service at the university are shown in Table 1 . The family medicine department has the highest number of circuit riders participating in the program. Ninety percent of circuit riders have been participating for 3 years or more, and $49 \%$ have participated for 5 years or more. The top three reasons circuit riders cite for participating in the program include (1) enjoyment of working with medical students, (2) support for training of students in rural/community sites, and (3) interacting with community preceptors.

Table 2 shows the ranked items by years at the university. There is no statistically significant association between years as faculty and the decision to rank any specific item. Those who have been at the university more than 10 years rank enjoying interacting with preceptors higher than the ranking given by those with less time at the university (2.6 versus 3.4 ). Those with more than 10 years at the university rank the item about counting toward the departmental curriculum contribution lower than those with less time at the university (4.2 versus 3.2). The highest rank for both groups was enjoying working with students. The second highest ranking for both groups was support for training students in rural/community sites.

Table 3 shows the ranked results by number of years circuit riding. There was no statistically significant association between years of circuit riding and the decision to rank any specific item. Those who have been circuit riding more than 5 years rank the item relating to enjoying the interaction with preceptors significantly higher than the ranking given by those who have been circuit riding $1-5$ years $(2.4$ versus 3.6 $(P<.001))$. Those who have been circuit riding for $1-5$ years rank liking to travel New Mexico higher than those who have been circuit riding longer (3.1 versus 4.2). The highest ranking for both groups was enjoying working with students. The second highest ranking for both groups was the item about supporting training students in rural/community sites. When we analyzed all items by medical specialty of the circuit rider, there were no statistically significant differences.

Circuit riders may choose to stay at the same site year after year or change sites. The majority of circuit riders $(58 \%)$ prefer returning to the same site. They cited the enjoyment of seeing the same practice and community year after year. "I got to know the preceptor and the

\section{Table 1}

\section{Characteristics of Circuit Riders}

\begin{tabular}{|c|c|}
\hline Specialty & $n(\%)$ \\
\hline Total & $39(100 \%)$ \\
\hline Family medicine & $13(33 \%)$ \\
\hline Psychiatry & $3(8 \%)$ \\
\hline Anesthesiology & $3(8 \%)$ \\
\hline Internal medicine & $2(5 \%)$ \\
\hline Basic science $\mathrm{PhD}$ & $2(5 \%)$ \\
\hline Pediatrics & $1(3 \%)$ \\
\hline Obstetrics and gynecology & $1(3 \%)$ \\
\hline Neurology & $1(3 \%)$ \\
\hline Emergency medicine & $1(3 \%)$ \\
\hline Pathology & $1(3 \%)$ \\
\hline Pediatric gastroenterology & $1(3 \%)$ \\
\hline Child psychiatry & $1(3 \%)$ \\
\hline Occupational medicine & $1(3 \%)$ \\
\hline Sleep medicine & $1(3 \%)$ \\
\hline Informatics & $1(3 \%)$ \\
\hline No response & $6(15 \%)$ \\
\hline \multicolumn{2}{|l|}{ Years at the university } \\
\hline $1-5$ years & $7(18 \%)$ \\
\hline $6-10$ years & $16(41 \%)$ \\
\hline $11-20$ years & $6(15 \%)$ \\
\hline$>21$ years & $4(10 \%)$ \\
\hline \multicolumn{2}{|l|}{ Years of circuit riding } \\
\hline $1-2$ years & $4(10 \%)$ \\
\hline $3-5$ years & $16(41 \%)$ \\
\hline$>5$ years & $19(49 \%)$ \\
\hline
\end{tabular}

Percentage totals may not equal $100 \%$ due to rounding. 
Table 2

Rank Results by Years at the University

\begin{tabular}{|c|c|c|c|c|c|c|}
\hline \multirow[b]{2}{*}{ Item } & \multirow{2}{*}{$\begin{array}{c}\text { Years } \\
\text { at the } \\
\text { University }\end{array}$} & \multirow{2}{*}{$\begin{array}{c}\text { Sample } \\
\text { Size }\end{array}$} & \multicolumn{2}{|c|}{ Number Ranking Item } & \multicolumn{2}{|c|}{ Rank } \\
\hline & & & $n(\%)$ & PValue* & Mean (SE) & $P$ Value** \\
\hline Enjoy working with students & $\begin{array}{l}1-10 \\
>10\end{array}$ & $\begin{array}{l}20 \\
15\end{array}$ & $\begin{array}{l}20(100 \%) \\
15(100 \%)\end{array}$ & - & $\begin{array}{l}1.5(0.2) \\
1.6(0.2)\end{array}$ & .68 \\
\hline Support training students in rural/community sites & $\begin{array}{l}1-10 \\
>10\end{array}$ & $\begin{array}{l}20 \\
15\end{array}$ & $\begin{array}{l}18(90 \%) \\
11(73 \%)\end{array}$ & .37 & $\begin{array}{l}2.5(0.3) \\
2.0(0.3)\end{array}$ & .33 \\
\hline Enjoy interacting with preceptors & $\begin{array}{l}1-10 \\
>10\end{array}$ & $\begin{array}{l}20 \\
15\end{array}$ & $\begin{array}{c}15(75 \%) \\
15(100 \%)\end{array}$ & .06 & $\begin{array}{l}3.4(0.2) \\
2.6(0.3)\end{array}$ & .03 \\
\hline Counts departmental contribution to curriculum & $\begin{array}{l}1-10 \\
>10\end{array}$ & $\begin{array}{l}20 \\
15\end{array}$ & $\begin{array}{l}15(75 \%) \\
13(87 \%)\end{array}$ & .67 & $\begin{array}{l}3.2(0.3) \\
4.2(0.4)\end{array}$ & .04 \\
\hline Like to travel around New Mexico & $\begin{array}{l}1-10 \\
>10\end{array}$ & $\begin{array}{l}20 \\
15\end{array}$ & $\begin{array}{l}15(75 \%) \\
11(73 \%)\end{array}$ & 1.00 & $\begin{array}{l}3.7(0.4) \\
3.6(0.2)\end{array}$ & .95 \\
\hline Have clinic and/or research in the area & $\begin{array}{l}1-10 \\
>10\end{array}$ & $\begin{array}{l}20 \\
15\end{array}$ & $\begin{array}{l}5(25 \%) \\
4(27 \%)\end{array}$ & 1.00 & $\begin{array}{l}4.2(0.9) \\
5.0(0.6)\end{array}$ & .49 \\
\hline
\end{tabular}

* Fisher's exact test

$* * t$ test

Table 3

Rank Results by Years Circuit Riding

\begin{tabular}{|c|c|c|c|c|c|c|}
\hline \multirow[b]{2}{*}{ Item } & \multirow{2}{*}{$\begin{array}{l}\text { Years } \\
\text { Circuit } \\
\text { Riding }\end{array}$} & \multirow[b]{2}{*}{$\begin{array}{c}\text { Sample } \\
\text { Size }\end{array}$} & \multicolumn{2}{|c|}{ Number Ranking Item } & \multicolumn{2}{|c|}{ Rank } \\
\hline & & & $n(\%)$ & P Value* & Mean (SE) & P Value** \\
\hline Enjoy working with students & $\begin{array}{l}1-5 \\
>5\end{array}$ & $\begin{array}{l}17 \\
18 \\
\end{array}$ & $\begin{array}{l}17(100 \%) \\
18(100 \%)\end{array}$ & - & $\begin{array}{l}1.6(0.2) \\
1.5(0.2)\end{array}$ & .72 \\
\hline Enjoy interacting with preceptors & $\begin{array}{l}1-5 \\
>5\end{array}$ & $\begin{array}{l}17 \\
18\end{array}$ & $\begin{array}{l}14(82 \%) \\
16(89 \%)\end{array}$ & .66 & $\begin{array}{l}3.6(0.3) \\
2.4(0.2)\end{array}$ & $<.001$ \\
\hline Support training students in rural/community sites & $\begin{array}{l}1-5 \\
>5\end{array}$ & $\begin{array}{l}17 \\
18\end{array}$ & $\begin{array}{l}14(82 \%) \\
15(83 \%)\end{array}$ & 1.00 & $\begin{array}{l}2.6(0.4) \\
2.1(0.2)\end{array}$ & .31 \\
\hline Counts departmental contribution to curriculum & $\begin{array}{l}1-5 \\
>5\end{array}$ & $\begin{array}{l}17 \\
18\end{array}$ & $\begin{array}{l}14(82 \%) \\
14(78 \%)\end{array}$ & 1.00 & $\begin{array}{l}3.4(0.4) \\
4.0(0.3)\end{array}$ & .22 \\
\hline Like to travel around New Mexico & $\begin{array}{l}1-5 \\
>5\end{array}$ & $\begin{array}{l}17 \\
18\end{array}$ & $\begin{array}{l}13(76 \%) \\
13(72 \%)\end{array}$ & 1.00 & $\begin{array}{l}3.1(0.3) \\
4.2(0.3)\end{array}$ & .008 \\
\hline Have clinic and/or research in the area & $\begin{array}{l}1-5 \\
>5\end{array}$ & $\begin{array}{l}17 \\
18\end{array}$ & $\begin{array}{l}3(18 \%) \\
6(33 \%)\end{array}$ & .44 & $\begin{array}{l}3.7(1.5) \\
5.0(0.4)\end{array}$ & .26 \\
\hline
\end{tabular}

* Fisher's exact test

**t $t$ test

staff. It is easier to work with people you already know." "It was a pleasant experience, and the second time they treated me as an old friend."

Several return to communities in which they have had interactions in the past. Some have lived or practiced in these communities previously. Of those choosing to change sites, $29 \%$ liked the experience of meeting new preceptors and seeing new practices. "I like to meet new preceptors and see how different practice groups work." Thirteen percent went wherever they were assigned or needed.
The most common difficulties with the program are time related. Scheduling time away from clinic and coordinating the students', preceptors', and the circuit riders' schedule were seen as common problems. "Planning when to do the midterm visit to accommodate the student's schedule without bumping too many of my own patients from their appointments [is a problem]. I have to wait until the students have started and have worked out their schedule with the preceptor before I block a clinic day of my own." Lack of departmental support was also listed as a barrier. "I'm the only one in 
my department who circuit rides, and there is absolutely no positive feedback from the chair or anyone else." Several circuit riders commented that the distances involved in getting to the rural sites were a problem in our rural but geographically large state. A lack of motivation or preparation on the part of the student was also cited as an occasional issue.

\section{Discussion}

Our findings reveal that circuit riders are motivated primarily by their enjoyment of working with medical students, their support for community-based education, and the enjoyment they get from interacting with community preceptors. Faculty who had been circuit riding for the longest time ranked interacting with preceptors significantly higher. This may reflect the long-term relationships that many circuit riders have established with community preceptors over the years, since they have often returned to the same sites. We also surmise that our longest-term circuit riders are truly committed to community-based education and value the time and energy it takes to teach our students.

Administrative policies such as rewards for educational activities are not strong motivators for circuit rider participation, but they can pose barriers.

It is important to note that faculty who had been at the university for less than 10 years ranked receiving credit for educational work higher than faculty who had been at the university for more than 10 years. This may reflect the recent trend toward more quantitative measurement of educational time for faculty. Balancing time, clinical responsibilities, and educational responsibilities are the challenges that need to be addressed to allow circuit riders to continue to perform their function.

This study did not address how effective circuit riders are at their roles as viewed by the students or community preceptors. This is an area of future study of the program.
The majority of circuit riders coming from the Department of Family and Community Medicine are likely reflective of two issues. First is that the majority of sites are family medicine sites, and faculty often enjoy making and renewing connections with practitioners of the same specialty around the state. Second, the Department of Family and Community Medicine in our institution has a commitment to community-based education and rewards educational efforts of faculty in this area. However, the program would not be possible without the input, cooperation, and support of multiple departments in the university.

\section{Conclusions}

The use of circuit riders from a variety of disciplines is one strategy for maintaining contact with volunteer community preceptors and their medical students. Circuit riders are primarily motivated by their enjoyment of working with students and preceptors in the community. The effectiveness of this type of program is presently being evaluated.

Corresponding Author: Address correspondence to Dr Solan, 2400 Tucker NE, MSC 09 5040, Albuquerque, NM 87131-0001. 505-272-2165. Fax: 505-272-8045.BSolan@salud.unm.edu.

\section{REFERENCES}

1. Green LA, Fryer GE Jr, Yawn BP, Lanier D, Dovey SM. The ecology of medical care revisited. N Engl J Med 2001;344(26):2021-5.

2. Bowen JL, Irby DM. Assessing quality and costs of education in the ambulatory setting: a review of the literature. Acad Med 2002;77(7):621-80.

3. Liaison Committee on Medical Education. Function and structure of a medical school 2004 (updated February 2007). www.lcme.org/functions2007feb.pdf. Accessed June 13, 2007.

4. Suzewits J. Preceptor site visit. Fam Med 2002;34(4):204-11.

5. Moses SE, Dorsch JN, Kellerman R. The RAFT approach to academic detailing with preceptors. Fam Med 2004;36(5):316-8. 